\title{
EL RESUCITADO DE PUENTE GENIL, OBRA DE ALONSO DE MENA Y ESCALANTE. \\ (APORTACIÓN DOCUMENTAL PARA EL ESTUDIO DE UNA IMAGEN DEVOCIONAL)
}

\author{
GERARDO GARCÍA LEÓN \\ Consejería de Cultura. Junta de Andalucía
}

\begin{abstract}
Resumen
La escultura de Cristo Resucitado que se venera en la localidad cordobesa de Puente Genil venía siendo incluida, desde hace años, dentro de la producción del escultor granadino Alonso de Mena y Escalante. Ahora se dan a conocer los documentos inéditos que demuestran que la obra fue encargada al pintor Alonso de Gálvez, vecino de Écija (Sevilla), quien a su vez, encomendó la talla de la escultura a Alonso de Mena, y luego hizo su policromía en 1636. Así mismo, se subraya que este ejemplo de intermediación artística pudo estar en el origen de otras esculturas atribuidas a Alonso de Mena que se conservan en Écija.
\end{abstract}

Palabras clave

Escultura barroca, Cristo Resucitado, Alonso de Mena y Escalante, Alonso de Gálvez, Granada, Écija, Puente Genil

\section{THE RISE OF PUENTE GENIL. WORK OF ALONSO DE MENA Y ESCALANTE}

\begin{abstract}
The sculpture of Christ resurrected found in Puente Genil, Córdoba has for a long time been thought to be the work of the sculptor Alonso de Mena y Escalante from Granada. Previously unseen documents have now been discovered that show that the piece was originally commissioned to the painter Alonso de Gálvez from Écija, Seville and that he in turn commissioned the piece to Alonso de Mena y Escalante and then later Gálvez made his polychrome in 1636. This artistic exchange could also be behind other sculptures in Ecija that have been attributed to Alonso de Mena y Escalante.
\end{abstract}

Key words

Barroque sculpture, Christ resurrected, Alonso de Mena y Escalante, Alonso de Gálvez, Granada, Écija, Puente Genil 
Al examinar con detenimiento la fortuna crítica del artista Alonso de Mena y Escalante hallamos que, pese a tratarse de una figura apreciada y reconocida por la historiografía clásica, los resultados siempre fueron escuetos, compuestos de referencias aisladas, de atribuciones infundadas, de afirmaciones erróneas y de frecuentes y contin uas confusiones con la figura de su hijo, el afamado Pedro de Mena Medrano. Desde que en 1952 Antonio Gallego Burín reivindicara su personalidad y ofreciera la primera biografía documentada del escultor Alonso de Mena y Escalante, con motivo de la conmemoración del tercer centenario de la muerte de Juan Martínez Montañés ${ }^{1}$, ha sido constante la atención prestada por la historiografía artística a este personaje, cuya potencia creadora y notable influjo suponen un punto de inflexión en el estudio de la historia de la escultura andaluza del primer barroco.

En 2013 han sido publicados los resultados de un ambicioso proyecto de investigación sobre la escultura barroca andaluza e hispanoamericana de ese periodo, que ha sido llevado a cabo por profesores de las Universidades de Granada, Sevilla y México. Dicha obra aparece encabezada por un completo e interesante estudio, dirigido por Lázaro Gila Medina, donde se recoge y actualiza toda la bibliografía que se ha ocupado de la figura del escultor Alonso de Mena, y en el que se aporta abundante y novedosa documentación para conocer su biografía y ampliar el catálogo de su obra artística, al tiempo que se ofrecen referencias fundamentales sobre otras obras desaparecidas que, a partir de ahora, quedan adscritas a la ingente producción del artista granadino ${ }^{2}$.

Una de las obras cuya atribución a Alonso de Mena se considera unánime y segura es el Resucitado de Puente Genil, si bien hasta este momento careciendo de la más mínima referencia documental. Como es bien conocido, la cofradía de Nuestro Padre Jesús Resucitado, de la parroquia de Nuestra Señora del Carmen de Puente Genil, venera desde el año 1950 una imagen de Cristo Resucitado que está fechada en 1636, y a la que diversos especialistas han venido vinculando con la producción del artista granadino Alonso de Mena y Escalante y su taller ${ }^{3}$. Se trata de una escultura que mide $152 \mathrm{~cm}$, está apoyada sobre una peana de $11 \mathrm{~cm}$, y lleva inscrito el año 1636 en la parte interior de la peana. La pieza ha sido objeto de varias restauraciones, acometidas con diversa fortuna por Antonio Muñoz Montaño (1950), Rafael Díaz Pino (1959), Miguel Arjona Navarro (1985) y José Manuel Cosano Cejas (2011).

En 2010 la imagen sufría diferentes daños debidos al deterioro de los ensambles de las maderas, con la consiguiente aparición de grietas en su encarnadura. El aparejo también estaba agrietado, existiendo pequeños desprendimientos del estofado y en zonas muy puntuales de la encarnadura. Dicha encarnadura mostraba un tono agrisado y opaco, fruto del oscurecimiento del óleo empleado en la policromía, que daba a la obra un aspecto impropio de su antigüedad y calidad artística. El proceso de restauración llevado a cabo en 2011 por José Manuel Cosano Cejas ha devuelto a la imagen gran parte de su nobleza y calidad artística originales. A través de los procesos de consolidación, limpieza general y reintegración, se han eliminado las grietas que presentaba la escultura, así como los emplastes deteriorados y puntas metálicas, se ha recuperado gran parte de la encarnadura original, reintegrando las lagunas con acuarelas y pigmentos restauro al barniz, y se han reparado los desprendimientos que existían en la policromía del manto y la peana ${ }^{4}$ (figs. 1-4).

\footnotetext{
${ }^{1}$ Gallego Burín, 1952.

2 Gila Medina, 2013: 17-82.

3 Rivas Carmona, 1982: 105-107. Villar Movellán, 1990: 348-352. Villar Movellán 1989: 38-38 y 70. Aroca Lara, 1988: 185-194. Aires Rey, 1990: 356. Aranda Doncel/Jiménez Rodríguez/Villar Movellán, 1999: 410-513. Sánchez-Mesa Martín, 2003: 151-168. Gila, 2015: 312.

4 Agradezco a José Manuel Cosano Cejas por las fotografías proporcionadas para este artículo y por haberme permitido consultar la Memoria sobre la restauración de la imagen de Jesús Resucitado de Puente Genil, que llevó a cabo en Sevilla en 2011.
} 


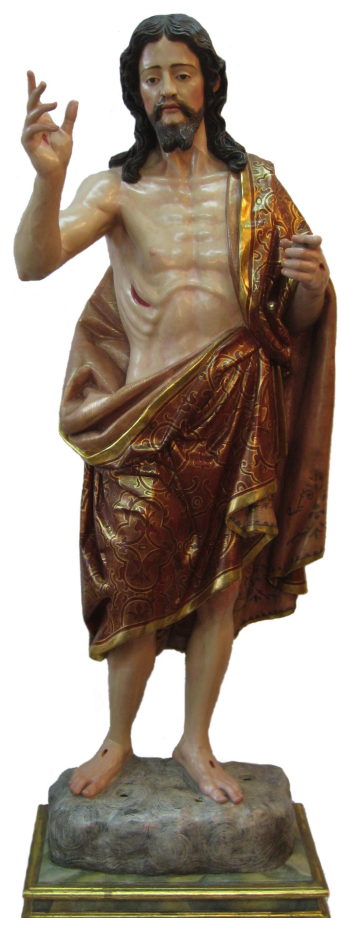

Fig. 1. Cristo Resucitado. Parroquia del Carmen. Puente Genil (foto José Manuel Cosano Cejas)

La tradición local de Puente Genil establece el origen y la procedencia de este Resucitado en la desaparecida ermita de Santa Catalina, aunque otras fuentes afirman que recibió culto en la ermita de la Vera Cruz hasta el año 1877. Lo que sí está confirmado es que, desde este santuario, pasó a la iglesia de Nuestra Señora del Carmen a partir de $1950^{5}$.

Por tratarse de cuestiones difíciles de resolver, principalmente debido a la ausencia de documentación histórica o de referencias bibliográficas solventes que impiden reconstruir su historia, y que han influido negativamente en los diversos avatares que ha sufrido la escultura a lo largo de los siglos, no son éstos los aspectos sobre los que ahora nos interesa centrarnos.

Gracias a documentos inéditos que se conservan en el Archivo de Protocolos Notariales de Écija, y que en estos momentos damos a conocer, pensamos que quedan refozadas las atribuciones anteriores y estimamos que la escultura de Cristo Resucitado que hoy se venera en la parroquia del Carmen de Puente Genil pudo ser realizada en la ciudad de Granada en el año 1635 por el escultor Alonso de Mena, en cumplimiento de un encargo hecho por el pintor Alonso de Gálvez, artista vecino de Écija, quien posteriormente llevó a cabo su policromía, a comienzos de 1636.

Basamos nuestra afirmación en dos documentos fundamentales que aclaran algunos datos básicos sobre su creación. El primero de ellos es una escritura de compromiso y obligación de pago suscrita en Écija el día 18 de marzo de 1636 entre Antonio de Gálvez y Antonio Ruiz Pastrana, vecinos de la Puente de don Gonzalo (actual Puente Genil), de una parte, y de la otra, Alonso de Gálvez, maestro pintor vecino de Écija. En este documento se declara "que, por quanto Alonso de Gálbez, pintor beçino desta çiudad, estaba obligado a haçer de escultura y dorado una hechura de la Resurreçión de Nuestro Señor Jesucristo, por çierta cantidad de marabedís, y porque el susodicho á cunplido con su obligaçión y hecho la dicha hechura a nuestro contento y satisfaçión y se lo abemos satisfecho y pagado, menos doçientos y sesenta reales, y porque de presente estamos ynpusibilitados de podelle satisfaçer

5 Villar Movellán, 1990: 348-352. 
Fig. 2. Cristo Resucitado, detalle. Parroquia del Carmen. Puente Genil (foto José Manuel Cosano Cejas)

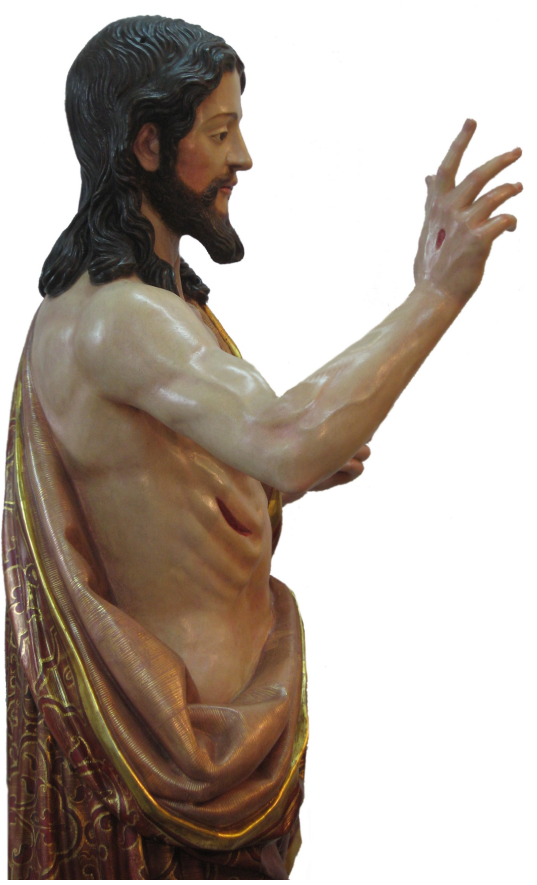

y pagar los dichos marabedís, le abemos pedido nos aguarde por ello y nos obligaremos a su satisfaçión y paga a çierto plazo, como adelante yrá declarado".

En consecuencia, queda demostrado que dos vecinos de Puente Genil llamados Antonio de Gálvez y Antonio Ruiz Pastrana encargaron la talla y policromía de una imagen de Cristo Resucitado al pintor ecijano Alonso de Gálvez; que en marzo de 1636 el compromiso había sido cumplido a satisfacción de los clientes; que la escultura había sido entregada; y que, del coste final de la obra, quedaba pendiente de abono al pintor la suma de 260 reales.

El segundo documento es una escritura de testamento otorgada en Écija seis meses antes de la anterior, el día 4 de septiembre de 1635, por el citado pintor Alonso de Gálvez, hallándose enfermo de gravedad y en cama, en su casa de la calle de la Torrecilla del Gallo, situada en la collación de Santa Cruz. En este documento, tras efectuar balance de los legados y donaciones hechas a lo largo de su vida a favor de sus hijos, el pintor relaciona los principales trabajos que estaba realizando en el momento de su enfermedad y reconoce las deudas que mantenía con algunos artistas que habían colaborado en su actividad profesional. En una de estas cláusulas se dice textualmente: "Declaro que debo a Alonso de Mena, beçino de Granada, escultor, a la calle Elbira, treçientos reales de la hechura de un Cristo rezuçitado" "?

En base a esta segunda prueba documental sabemos que Alonso de Gálvez había encargado la talla de una imagen de Cristo Resucitado al escultor granadino Alonso de Mena, que la obra ya estaba concluida en septiembre de 1635 (momento en que fue redactado y otorgado el testamento) y que aún se debían al escultor 300 reales por este trabajo.

Por tanto, podemos concluir que el encargo de la imagen se hizo directamente al pintor ecijano Alonso de Gálvez, tanto en lo relativo a escultura como a policromía, y que

${ }^{6}$ Escritura de obligación y reconocimiento de deuda a favor de Alonso de Gálvez, pintor vecino de Écija, 18 de marzo de 1636, Archivo de Protocolos Notariales de Écija (A.P.N.E.), legajo 1603, ff. 289r-291v. Los deudores se comprometieron a pagar los 260 reales para el día de Santiago de ese mismo año 1636.

7 Testamento de Alonso de Gálvez, 4 de septiembre de 1635, A.P.N.E., legajo 1594, ff. 990r-995v. 
dicho artífice, probablemente, subcontrató la talla en madera de la obra con el granadino Alonso de Mena. Resta por dilucidar la fecha y el lugar exactos del encargo inicial hecho por los dos vecinos de Puente Genil, así como el precio total pactado para la imagen, que comprendería la talla de la madera y su policromía. Es preciso indicar que después de una completa revisión de los protocolos notariales de esos años conservados en Écija, no ha sido posible localizar más referencias documentales sobre este asunto. Desconocemos si el encargo inicial pudo ser realizado en Écija y quizá la escritura no se conserve en la actualidad, o bien si dicho contrato pudiera haber sido otorgado ante algún escribano de la misma localidad de Puente Genil. Otra incógnita sin resolver es si llegó a existir un contrato otorgado en Granada entre Alonso de Mena y Alonso de Gálvez.

La declaración hecha por Alonso de Gálvez en su testamento afirma que debía 300 reales a Mena por la hechura del Resucitado, pero no aclara si ésta era la cantidad total en la que ambos artistas concertaron la obra, o si se trataba del resto que aún tenía pendiente de abonar. En este sentido conviene recordar el coste de algunas obras que Alonso de Mena había realizado unos años antes. En 1618 se obligaba a realizar, en colaboración con el pintor Francisco Ruiz, una figura de Cristo Resucitado $(145 \mathrm{~cm})$ para Setenil de las Bodegas (Cádiz), por la que habían de cobrar 352 reales. En 1620 cobró 400 reales por un San Francisco (124 $\mathrm{cm}$ ) para el convento de Nuestra Señora de Consolación de Alcalá la Real (Jaén), y 264 reales en 1622, por la hechura de un San Juan Bautista $(110 \mathrm{~cm})$ para la iglesia de Cozvíjar (Granada). En dicho año se comprometió a realizar un San Miguel $(160 \mathrm{~cm})$ para el mercader granadino Miguel Ruiz por 495 reales, incluyendo las andas procesionales con su tornillo y horquillas ${ }^{8}$.

Teniendo en cuenta que el pintor ecijano Alonso de Gálvez, siempre incluyendo talla y policromía, había cobrado 600 reales en 1624 por la realización de un San Pascual; la misma cantidad por una figura del Ángel de la Guarda, en 1625; y 770 reales por una imagen de la Virgen con el Niño Jesús, en $1630^{\circ}$, nos inclinamos a pensar que muy probablemente el Resucitado de Puente Genil fuera contratado por una cantidad que no superaría los 700 reales. Debe advertirse que, a causa de la desnudez de la figura, el costoso pan de oro sólo estaría destinado al estofado del manto, de menor superficie que las vestiduras de las imágenes antes mencionadas.

A título ilustrativo diremos que, por estos años, en Sevilla Juan de Mesa realizó en 1620 el Cristo Resucitado $\left(125 \mathrm{~cm}\right.$ ) de Tocina (Sevilla) por 500 reales $^{10}$ y, en 1626, hizo el San Ramón Nonato $(178 \mathrm{~cm})$ para los mercedarios descalzos de Sevilla, actualmente en el Museo de Bellas Artes, por 900 reales $^{11}$. A otra escala, y en consonancia con la calidad y fama de su gubia, mencionemos que en 1634 Juan Martínez Montañés talló la imagen de San Bruno $(172 \mathrm{~cm})$, para la Cartuja de Sevilla por 4.400 reales, actualmente en el citado Museo sevillano ${ }^{12}$ y que, en los dos años siguientes, contrató las imágenes sedentes de San Juan Evangelista $(138 \mathrm{~cm})$ y San Juan Bautista $(138 \mathrm{~cm})$ para la iglesia conventual de Santa Paula de Sevilla, por 4.400 reales y 5.500 reales, respectivamente ${ }^{13}$.

Pero existe otro aspecto relevante sobre la historia del Resucitado de Puente Genil que aún permanece oculto, pues tampoco ha sido posible aportar más referencias sobre la identidad de los clientes que encargaron la imagen -aparte de sus nombres- ni conocer si representaban a una hermandad o congregación, o si actuaban en nombre de alguna fábrica parroquial, conventual, o alguna otra institución.

\footnotetext{
${ }^{8}$ Gila Medina, 2013: 17-82.

${ }^{9}$ García León/ Martín Ojeda (obra en prensa).

${ }^{10}$ Hernández Díaz, 1972: 60.

${ }^{11}$ Ibidem, 73.

12 Hernández Díaz, 1987: 239.

13 Ibidem, 243-245.
} 


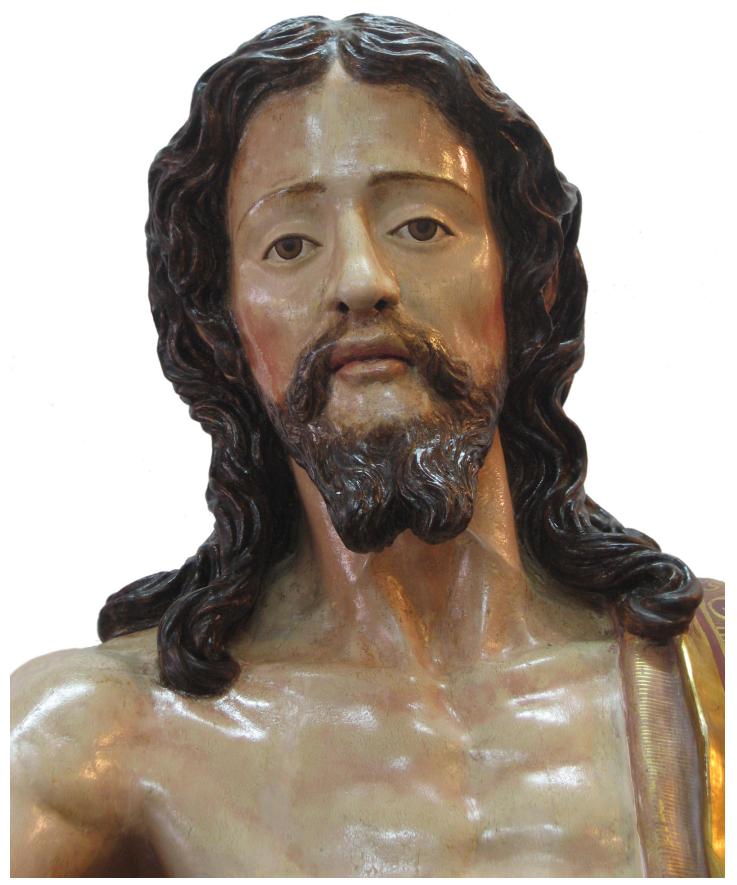

Fig. 3. Cristo Resucitado, detalle. Parroquia del Carmen. Puente Genil (foto José Manuel Cosano Cejas)

En cuanto a la figura de Alonso de Gálvez, cuya biografía y catálogo de obras se hallan en vías de publicación, podemos adelantar que se trataba de un pintor y dorador probablemente nacido en Écija, al que hallamos documentado en dicha ciudad entre 1608 y 1638, y que era hijo de Alonso Hernández y de María Díaz. De formación desconocida, son numerosas las obras realizadas a lo largo de su actividad profesional, destacando la pintura y dorado de diferentes retablos en las parroquias de San Gil (1615), Santa María (1626), Santa Bárbara (1627), Santa Cruz (1635), y en los conventos de Santo Domingo (1623) y del Carmen Calzado (1635) ${ }^{14}$. También está documentada su participación en los encargos de varias esculturas, en 1625, para la cofradía del Santo Ángel de la Guarda, del convento de Santa Ana, para el convento de monjas clarisas de Santa Inés y para la parroquia mayor de Santa Cruz ${ }^{15}$. Además, contrató la realización de otras imágenes para particulares de Écija (1624-1630), así como una talla para la cofradía de las Ánimas del Purgatorio de la parroquia de Santa Bárbara (1631). Entre sus trabajos documentados en la provincia de Córdoba destacan el dorado de uno de los retablos de la iglesia del Colegio de la Compañía de Jesús de Montilla (1616) y el encargo de la imagen de Cristo Resucitado de Puente Genil (1635), que ahora damos a conocer ${ }^{16}$.

El caso de la escultura que nos ocupa puede servir como ejemplo claro e ilustrativo de la actividad artística que se desarrollaba en ciertos núcleos urbanos de carácter secundario, directamente influenciados por los dos grandes focos artísticos sevillano y granadino, pero capaces de abastecer en un discreto porcentaje la demanda de productos artísticos generada por la clientela local y por la que acudía a ellos desde poblaciones cercanas. Ciudades como Antequera, Cádiz, Córdoba, Ecija, Guadix, Jaén, Jerez de la Frontera, Priego de Córdoba o

\footnotetext{
${ }^{14}$ García León/Martín Ojeda (obra en prensa). La mayor parte de las obras documentadas de este autor no se conservan en la actualidad.

15 Villa Nogales/Mira Caballos, 1993: 82-84.

16 García León/Martín Ojeda (obra en prensa). En esta obra aparecen transcritos todos los contratos relativos a las obras mencionadas, incluida la escritura de reconocimiento de deuda del Resucitado de Puente Genil.
} 
Málaga mantuvieron una actividad artística constante, desarrollada por artistas locales o procedentes de Sevilla, Granada e incluso Flandes o Italia ${ }^{17}$. La ciudad de Écija fue uno de estos centros secundarios de creación artística cuya producción excedió el ámbito estrictamente local, pues ya desde el siglo XVI hallamos numerosos casos de artífices ecijanos, o afincados en Écija, realizando obras artísticas para otras poblaciones sevillanas y cordobesas como Peñaflor, Osuna, Estepa, Marchena, Fuentes, Morón, Utrera, Palma del Río, Guadalcázar, Santaella, Montilla, Puente Genil, Montalbán, etc ${ }^{18}$. En este sentido ya han sido estudiadas las obras del carpintero ecijano Gregorio Tirado en el santuario de Nuestra Señora de Consolación de Utrera (Sevilla) (1578) o las del escultor y retablista activo en Écija Juan Fernández de Lara, que llevó a cabo los retablos colaterales de la parroquia de la Asunción de Priego de Córdoba (1625-1627), el retablo para la cofradía del Santísimo Sacramento de Montilla (Córdoba) (1630) y el retablo mayor de la iglesia conventual de Santa Clara de Marchena (Sevilla) (1641) ${ }^{19}$.

En cuanto al hecho de que el encargo de la escultura de Puente Genil se realizara a un pintor, existen multitud de casos similares en los que estos artífices actuaban como agentes artísticos y actores principales en los contratos de imágenes devocionales, pues no en vano, eran ellos los que, con su policromía, otorgaban a las tallas la apariencia humana y realista, gracias a las carnaciones y ricos estofados que, por lo general, resultaban mucho más costosos que la propia talla en madera.

Los historiadores del arte que estudian el arte Barroco insisten en señalar la presión y el control que los gremios siempre mantuvieron para que pintores, escultores o ensambladores no asumieran contratos que no fueran de su oficio o arte. La lucha contra el intrusismo profesional fue una constante entre estos colectivos durante los siglos XVI y XVII, utilizando siempre la reglamentación legal contenida en las ordenanzas gremiales y, sobre todo, convirtiendo a los exámenes de maestría en el requisito obligatorio y fundamental mediante el que se demostraban y verificaban las aptitudes necesarias para el desempeño de cualquier oficio artístico.

Un ejemplo evidente de este enfrentamiento fue la denuncia que el pintor Francisco Pacheco presentó en 1622, en nombre del gremio de pintores sevillanos, contra su amigo Juan Martínez Montañés, porque éste había incluido la policromía en uno de sus contratos ${ }^{20}$. No obstante, este cumplimiento no fue siempre tan estricto, pues en 1635 el pintor Pablo Legot vendió un Cristo crucificado, actualmente con el título de Cristo de la Fundación, a la cofradía sevillana de Nuestra Señora de los Ángeles, vulgo de los negritos. Debido a ese contrato se consideró durante años que el pintor era el autor de la imagen hasta que, durante la restauración que el escultor Agustín Sánchez Cid realizara sobre esta obra en 1940, se encontró en su interior un documento que informaba de la autoría y fecha de realización de la misma. Según consta en dicho documento, la obra había sido tallada en Sevilla en 1622 por el escultor Andrés de Ocampo. Por la imagen, que fue vendida trece años después de su realización, Pablo Legot cobró 1.400 reales $^{21}$.

Para finalizar esta breve contribución a la historia de la imagen de Cristo Resucitado de Puente Genil, cuya autoría podría quedar definitivamente adscrita a la producción documentada del escultor Alonso de Mena y Escalante, deseamos poner de manifiesto que, una vez demostrado este ejemplo de colaboración entre artistas granadinos y ecijanos, será preciso estudiar con una nueva óptica la catalogación que la historiografía artística ha venido otorgando a determinadas piezas de esta época conservadas en Écija. Teniendo en cuenta

17 Romero Torres, 2007: 138-149.

18 García León, 2007: 190-201.

19 Aroca Lara, 1986: 150-201. Villa Nogales/Mira Caballos, 1993: 127-128. Villa Nogales/Mira Caballos, 2002: 221-237. Zurita Pérez/ Marín Molina, 2014: 25-30.

${ }^{20}$ Hernández Díaz, 1987: 29. Asensio Toledo, 1886: 44-48.

${ }^{21}$ Sancho Corbacho, 1930: 306-307. Valdivieso/Serrera, 1995: 274. 


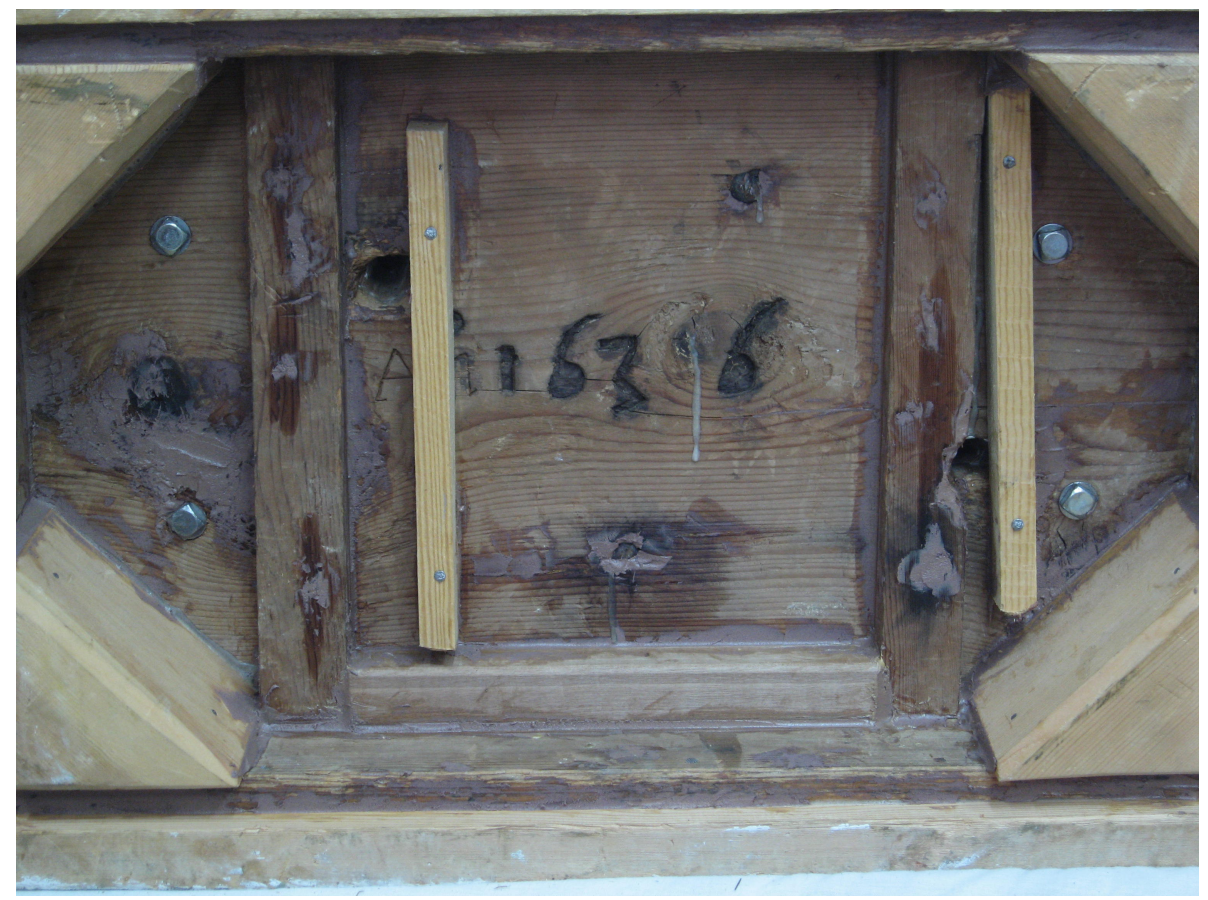

Fig. 4. Cristo Resucitado, detalle peana. Parroquia del Carmen. Puente Genil (foto José Manuel Cosano Cejas)

que Alonso de Gálvez contrató la ejecución de varias esculturas para hermandades ecijanas, en concreto para la mencionada cofradía del Santo Ángel de la Guarda, del convento de frailes franciscanos terceros de Santa Ana, quizá sería oportuno realizar un nuevo análisis de piezas como el Cristo de la Yedra, que perteneció a la mencionada cofradía, o el San Juan Bautista y el San Juan Evangelista del convento de Santa Inés del Valle, cuyas influencias granadinas ya han sido apuntadas ${ }^{22}$. En este sentido, en los últimos años viene siendo aceptada la atribución al escultor Alonso de Mena de la imagen del Cristo de las Penas que, fechada en 1644, fue titular de la cofradía de la Caridad del Santo Cristo de las Penas, que actualmente se conserva en la iglesia del antiguo convento del Carmen Calzado de Écija ${ }^{23}$.

\footnotetext{
${ }^{22}$ Hernández Díaz/Sancho Corbacho/Collantes de Terán, 1951: 190. González Gómez, 2011: 77-123.

${ }^{23}$ Romero Torres, 2013: 379-380. Gila, 2015: 210.
} 
El Resucitado de Puente Genil, obra de Alonso de Mena y Estepa

Bibliografía

Aires Rey, J. L.: Puente Genil Nazareno. Antropologia, historia, arte, tradición. Córdoba: Diputación de Córdoba-Ayuntamiento de Puente Genil. (1990)

Aranda Doncel, J./Jiménez Rodríguez, J. S./Villar Movellán, A.: "Puente Genil". En: La Pasión de Córdoba, [IV]. Sevilla: Ediciones Tartessos, (1999), pp. 410-513.

Aroca Lara, Á.: "La Escultura Cordobesa del Seiscientos". En: Catálogo de la exposición Antonio del Castillo y su época. Córdoba: Diputación Provincial, (1986), pp. 150-201.

Aroca Lara, Á.: "El Resucitado de Puente Genil". En: Boletín de la Real Academia de Córdoba de Ciencias, Bellas Letras y Nobles Artes, [115] Córdoba, (1988), pp. 185-194.

Asensio Toledo, J. M.: Francisco Pacheco. Sus obras artísticas y literarias. Sevilla: Imp. E. Rasco. (1886)

Gallego Burín, A.: Un contemporáneo de Montañés. El escultor Alonso de Mena y Escalante. Sevilla: Ayuntamiento de Sevilla. (1952)

García León, G.: "El Barroco en la Comarca de Écija”. En: Andalucía Barroca. Exposición Itinerante. Sevilla: Consejería de Cultura, Junta de Andalucía, (2007), pp. 190-201.

García León, G./Martín Ojeda, M. (obra en prensa): Documentos inéditos para la Historia del Arte en Écija. Siglos XVI y XVII.

Gila Medina, L.: “Alonso de Mena y Escalante (1587-1646). Escultor, ensamblador y arquitecto: nueva aproximación biográfica y nuevas obras”. En: La consolidación del Barroco en la escultura andaluza e hispanoamericana. Granada: Universidad de Granada, (2013), pp. 17 82.

Gila, L. (comisario): Iuxta Crucem. Arte e iconografía de la Pasión de Cristo en la Granada Moderna, siglo XVI-XVIII. Granada: Diputación Provincial. (2015)

González Gómez, J. M.: "El esplendor de la carne o la madera estremecida. La escultura barroca en Écija”. En: Écija Barroca. Écija: Ayuntamiento, (2011), pp. 77-123.

Hernández Díaz, J./Sancho Corbacho, A./Collantes de Terán, F.: Catálogo Arqueológico y Artístico de la Provincia de Sevilla, [IV]. Sevilla: Diputación Provincial. (1951)

Hernández Díaz, J.: Juan de Mesa. Escultor de imaginería (1583-1627). Sevilla: Diputación Provincial. (1972)

Hernández Díaz, J.: Juan Martínez. Montañés (1568-1649). Sevilla: Ediciones Guadalquivir, (1987)

Rivas Carmona, J.: Puente Genil monumental. Puente Genil: Col. Anzur. (1982)

Romero Torres, J. L.: "Los Focos Artísticos". En: Andalucía Barroca. Exposición Itinerante. Sevilla: Consejería de Cultura, Junta de Andalucía, (2007), pp. 138-149.

Romero Torres, J. L.: "Juan Pérez Crespo, escultor y padrino de La Roldana. Su trayectoria Lorca-Granada-Sevilla". En: Laboratorio de Arte [25]. Sevilla, (2013), pp. 379-380.

Sánchez-Mesa Martín, D.: "Juan de Mesa y la escultura andaluza de su tiempo. Nuevas obras de Alonso de Mena". En: Juan de Mesa ((1627-2002). Visiones y revisiones. Córdoba: Universidad, (2003), pp. 151-168.

Sancho Corbacho, H.: Contribución documental al estudio del arte sevillano. Documentos para la Historia del Arte en Andalucia, [vol. II]. Sevilla: Universidad. (1930)

Valdivieso, E./Serrera, J. M.: Historia de la Pintura Española. Escuela sevillana del primer tercio del siglo XVII. Madrid: CSIC. (1995)

Villa Nogales, F. de la/Mira Caballos, E.: Documentos inéditos para la bistoria del arte en la provincia de Sevilla. Carmona: Ayuntamiento de Carmona. (1993) 
Villa Nogales, F. de la/Mira Caballos, E.): "Juan Fernández de Lara: un escultor en la Écija del siglo XVII". En: Archivo Hispalense [259-260], Sevilla, (2002), pp. 221-237.

Villar Movellán, A.: Las escuelas del barroco y la imaginería de Puente Genil. Córdoba: Universidad de Córdoba. (1989)

Villar Movellán, A.: "Alonso de Mena, nexo de las escuelas andaluzas" En: Pedro de Mena y su época. Actas del simposio nacional. Sevilla: Consejería de Cultura, Junta de Andalucía, (1990), pp. 348-352.

Zurita Pérez, Fernando/Marín Molina, J. F.: "Juan Fernández de Lara: un artista barroco en el primerizo barroco prieguense”. En: Soledad [25], Priego de Córdoba, (2014), pp. 25-30. 